\title{
LAS TEORÍAS NATURALISTAS DE ALEJANDRO SAWA Y LÓPEZ BAGO
}

Francisco Gutiérrez Carbajo

Profesor-tutor de la UNED, Madrid

Si Leopoldo Alas, Emilia Pardo Bazán y otros representantes del movimiento naturalista cuentan con una extensa bibliografia y sus obras se reeditan continuamente, no sucede lo mismo con los integrantes del denominado naturalismo radical. De Alejandro Sawa, que ha merecido estudios esclarecedores como los de Allen Phillips' e Iris M. Zavala², sólo una de sus novelas, La mujer de todo el mundo ${ }^{3}$ ha sido reeditada. De López Bago ni una sola obra se ha vuelto a publicar. Eduardo López Bago, autor de innumerables narraciones, no dispone hasta la fecha de un estudio comparable a los dedicados al autor de Iluminaciones en la sombra, aunque no escasean los trabajos sobre algunas de sus novelas o los que abordan su producción al estudiar la narrativa de finales de siglo.

Pattison, en su libro ya clásico El naturalismo español ${ }^{4}$, distingue a partir de 1886, una corriente espiritualista, que encuentra refuerzos en Francia y en la novela rusa, y una corriente cultivadora de un naturalismo extremado que tendría en Sawa y López Bago sus exponentes más significativos. Según Mercedes Etreros, estos autores pertenecen a la etapa de la plenitud naturalista, y el carácter erótico constituiría uno de los rasgos singularizadores de sus obras 5 .

' Phillips, A.: Alejandro Sawa, mito y realidad, Madrid, Turner, 1976.

2 Zavala, I. M.: Edición de Iluminaciones en la sombra, de Alejandro Sawa, Madrid, Alhambra, 1977.

${ }^{3}$ Sawa, A.: La mujer de todo el mundo (1885); nueva edición con prólogo de José Esteban, en Madrid, Moreno-Ávila editores, 1988.

4 Pattison, W. T.: El naturalismo español. Historia externa de un movimiento literario. Madrid, Gredos, 1965.

s Etreros, M.: «El naturalismo español en la década de 1881-1891", en Estudios sobre la novela española del siglo XIX, Madrid, CSIC, 1977, pp. 49-131. 
La narrativa naturalista de Sawa y López Bago la estudia igualmente Miguel Ấngel Lozano Marco en su trabajo: «El naturalismo radical: Eduardo López Bago. Un texto desconocido de Alejandro Sawa» ${ }^{6}$.

En las novelas El Periodista y La Prostituta, de Eduardo López Bago se centra especialmente el trabajo de Pierre Jourdan, "Les manifestations du naturalisme en Espagne: deux romans de López Bago...»’.

El naturalismo radical fue el tema de la ponencia del profesor Ivan Lissorgues, presentada en el «Congreso Internacional sobre realismo y naturalismo en España, en la segunda mitad del siglo XIX ${ }^{8}$, que se celebró en la Universidad de Toulouse, durante los días 3, 4 y 5 de noviembre de 1987.

No se ha prestado, sin embargo, suficiente atención a las ideas naturalistas que defienden estos autores y al modo cómo este código estético configura sus narraciones.

Con una postura muy lejana todavía del naturalismo radical, interviene López Bago en la polémica suscitada por La cuestión palpitante, en la que participaron, entre otros, Antonio Cánovas del Castillo, José Yxart, Luis Alfonso, Palacio Valdés, la propia condesa de Pardo Bazán y Ortega Munilla. A este último dirige López Bago una carta en El Progreso ${ }^{9}$, titulada Naturalistas e idealistas. En ella el autor de La Prostituta se muestra bastante moderado y admite que sus opiniones «son de mucha conformidad con la llamada escuela naturalista", aunque se apresura a añadir que existen puntos esenciales en los que no concuerda ni con Ortega Munilla ni con Luis Alfonso. Cree que los dos incurren en «exageraciones tales y tamañas, que ni el naturalismo ni el idealismo salen bien parados en el encuentro». Los dos adversarios están cegados por la pasión. Argumenta que la bondad, la verdad y la belleza son cualidades necesarias en la literatura, y «en cuanto a la moral, si también existe, será miel sobre hojuelas; pero si se queda en el tintero... no hay para qué echarla de menos... Nada ganan ni pierden los naturalistas con que se les acuse de escritores inmorales, y los idealistas con que los canonicen. Conviene sin embargo precisar que, si alguien lleva ventaja, es el escritor naturalista; pues, mintiendo los dos, no miente tanto el que exagera la verdad como el que la niega». Asegura, además, que la mayoría de los críticos piensa sólo en Zola al hablar de naturalismo. Junto a él merecen citarse, según López Bago, los nombres de Flaubert, Daudet y los Goncourt, que "armonizan perfectamente la verdad y la belleza».

La polémica sobre «la cuestión palpitante» arrecia con fuerza y nuestro

- En Anales de literatura española, Universidad de Alicante, (1983), núm. 2, pp. 341-360.

IRIS, 1981/1, CERLIAM, Université Paul Valery, Montpellier, pp. 69-105.

- Recogido en Realismo y naturalismo en España en la segunda mitad del siglo XIX, Actas del Congreso Internacional celebrado en la Universidad de Toulouse-le Mirail del 3 al 5 de noviembre de 1987, Barcelona, Anthropos, 1988.

- El Progreso. 3 de marzo de 1884. 
autor tercia de nuevo en esta controversia. En un artículo publicado en $L a$ Ilustración Militar ${ }^{10}$ se hace eco de la intensidad de la discusión y de la diversidad de lugares en los que ésta se suscita: «En el Ateneo, en los saloncillos de los teatros, en las Academias y hasta en las mesas de los cafés, no hablamos de otra cosa". Pero ahora los que defienden el idealismo «luchan con menos fe, con menos denuedo". Casi se baten en retirada... Alarcón, uno de los idealistas más significativos no ha vuelto a publicar y ha dejado la defensa de sus ideas en manos de Cañete y Luis Alfonso. Frente a los representantes de esta corriente se alinean los naturalistas: Galdós, Pereda, Palacio Valdés, Pardo Bazán y Eugenio Sellés. López Bago se refiere luego a la carta dirigida por Eduardo Calcaño al director de la Academia Española, don Víctor Balaguer, en la que se quejaba de la decadencia del arte, de la destrucción de todos los ideales por la mano negra del naturalismo y de la necesidad de poner en guardia a los hombres de buena voluntad, es decir, a los idealistas y tradicionalistas, entre los que cita a Cánovas del Castillo, Núñez de Arce, Campoamor, Alarcón, Valera, Menéndez Pelayo, etcétera, y arguye que dicha carta «incurre en graves equivocaciones». Como otros autores de su época, intenta formular una definición correcta del naturalismo y asegura que no se trata de una nueva secta; es más bien una reacción, una vuelta a ideas y valores muy antiguos. El naturalismo consiste, sobre todo, en una renuncia a los procedimientos románticos. «El naturalismo es la naturalidad en todo, la verdad en todo, lo humano en todo». Y no es un sistema sin ideal. «Al contrario, ese es nuestro ideal: la naturaleza».

Frente a estas ideas, otros autores como Valera defenderán más tarde que el naturalismo no es más que una forma degenerada del romanticismo. Por su parte, López Bago, que se mostraba ecléctico en el primero de los artículos citados y claramente defensor de las ideas naturalistas en el segundo, llevará más tarde esta defensa hasta sus límites más extremos, tarea en la que se siente apoyado por Alejandro Sawa. Ambos aprovechan los comentarios a algunas de sus obras para exponer el programa de este movimiento. López Bago escribe en el apéndice de Crimen legal, de Sawa, que esta novela supone el primer acto de valor que realiza el autor bajo «las nuevas banderas" del naturalismo. Advierte, sin embargo, en su colega una cierta indisciplina y exuberancia que denotan un desconocimiento a fondo de "nuestras ordenanzas»" ${ }^{\prime}$. Se observa ya en estas declaraciones la concepción militante que tiene el naturalismo para López Bago. Pero los excesos de Sawa pueden corregirse ya que su "imaginación joven» y su "cerebro potente» llegarán a crear "seres novelescos robustos y humanos, tratándolos

1" La Ilustración Militar, 20 de julio de 1884.

"S^wa, A.: Crimen legal, Madrid, Biblioteca del Renacimiento Literario, Juan Muñoz y Compañia editor, 1886. 
a lo médico»" ${ }^{12}$. Los caracteres señalados proceden más de su audacia que de la influencia romántica ${ }^{13}$.

Con caracterizaciones de una psicología diferencial muy elemental, López Bago define el estilo de Sawa como propio de un «temperamento nervioso-sanguineo, suelto, fuerte, robusto, con mucho calor, y poseyendo el instinto, raro en nuestra época, de la belleza material de los vocablos» ${ }^{14}$. Insiste en la exuberancia que se manifiesta en la poca concentración del idioma y asegura que las «inutilidades, las baratijas que ha traído de la casa de los románticos para vivir en la nuestra» las irá vendiendo poco a poco a los compradores de lo viejo.

Al naturalismo han llegado Sawa y López Bago después de «haberse postrado de rodillas, confundiéndose con la multitud de adoradores del SolHugo y hasta de las palideces de la luz byroniana»"s. Pero el naturalismo, por su índole analítica y experimental no puede desprenderse de la sátira, no puede renunciar a ese sello, a esa marca que caracteriza mejor a Diderot que a Voltaire, ya que, según nuestro autor, el primero fue ya naturalista y el segundo sólo ateo. Y ese retrato de la realidad es lo que convierte las producciones de Balzac, Sthendal y Zola en auténticas sátiras sociales. Este tratamiento de la realidad es una de las principales señas de identidad del "naturalismo de ahora, y en eso se parece al de Cervantes y Quevedo»"

Un requisito imprescindible para que el escritor naturalista pueda llevar a cabo de un modo científico su función es la labor de observación. Por ser un "observador incansable» consigue Sawa transmitirnos esa sensación de verdad.

López Bago no se contenta con señalar los rasgos diferenciadores de la escuela ni con limitar su análisis a las producciones singulares de Sawa, sino que aventura ciertos juicios sobre literatura comparada. Relaciona así las novelas del autor de Crimen legal con las obras de los escritores veristas italianos y asegura que Sawa es, «dentro de nuestro procedimiento, más artista que los franceses, menos faiseur que ellos, pero más italiano" ${ }^{17}$. Y respecto a estos últimos, guarda más parecido con Luigi Cappuana que con Giovanni Verga. Su talento de observación, su estudio preciso, exacto y minucioso de la realidad es comparable al del autor de Homo. Sawa y Cappuana ven la humanidad de un modo semejante y para confirmarlo analiza el cuento $L a$ Mula y la novela Monstruosidad del autor italiano. En estas narraciones, como en Crimen legal, se desarrolla una serie de movimientos psíquicos con

'SAwa, A.: Crimen legal, p. 254.

Ibidem, p. 254.

4 Ibidem, p. 252.

15 Ibidem, p. 253.

Ibidem, p. 256.

7 Ibidem, p. 257. 
vigorosos trazos, se presenta una historia resumida en sus crisis esenciales, se adivina un ímprobo trabajo de observación y deducciones. Y todo ello con el mérito añadido de que el autor ha sabido ocultarse en la historia relatada.

Como los veristas, Sawa es un observador y un artista, "pero menos desinteresado en la observación; y en cambio, como artista, más personal; sigue la única ley razonable que puede dictar toda estética: se esmera en anotar lo que ve como lo ve, y agrupa y explica los hechos según su filosofia particular. Todos los ángeles caídos del idealismo son deterministas $\rangle^{18}$.

La observación —el arma más eficaz al servicio de la función fabuladora de Sawa y de los naturalistas auténticos, según nuestro autor - viene siempre impulsada por el instinto de curiosidad. Y esta mirada lo primero que descubre es la maldad radical de la humanidad, «esas excrecencias y ese cáncer que hacen del corazón humano, visto de cerca, el objeto más asqueroso para nuestra observación $)^{19}$. El término más adecuado para definir la humanidad es el de canalla, tanto por la propia constitución del ser humano como por la forma como está organizada la sociedad. Por presentar la realidad tal como es, los naturalistas levantan una polvareda de odio, pero cuentan con ello, «como cuenta el operador con los gritos, los insultos y las imprecaciones que el dolor arranca del paciente; como cuenta el juez con los rencores de la familia del reo y con los del reo mismo, que, condenado por ladrón, se convertirá en asesino del que dictó los considerandos y resultandos de su sentencias" ${ }^{20}$.

López Bago recurre con frecuencia a la comparación de la función narradora con la del juez y, sobre todo, con la del médico. «Hacemos procesos y autopsias" afirma con frecuencia. Esta responsabilidad les hace soportar adversidades e incurrir en los mismos peligros en los que incurrieron Zola en Francia y Verga y Cappuana en Italia. De ahí pasa a señalar el «sello peculiar» del escritor naturalista que viene determinado por el odio que éste suscita entre los "puntales» de la sociedad: «la burguesía nociva, la inútil aristocracia, el absurdo clero" ${ }^{21}$.

Los naturalistas no cuentan por tanto con la complacencia de los «poderes de hoy» aunque sin duda serán reconocidos por el «inminente poder de mañana». Este odio lo provoca el retrato que los naturalistas llevan a cabo de la miseria humana; pero López Bago se apresura a confesar que la culpa no es suya, sino de la propia existencia de esa miseria, del hecho de que los miserables constituyan el modelo más frecuente para el narrador. Y como

\footnotetext{
Sawa, A.: Crimen legal, p. 261.

Ibidem, p. 261.

Ibidem, p. 262.

Ibidem, p. 263.
} 
no quieręn ser injustos con la verdad ni "pasar moneda falsa", no pueden llamar nobleza y buena ley a lo que no lo es.

Y si más arriba se ha hecho referencia a la continua apelación a la ciencia para caracterizar sus obras, López Bago define la novela Crimen legal de Sawa como un "caso de medicina»" y como "novela médico-social» subtitulará cada una de sus propias narraciones. La medicina es uno de los mejores exponentes de la ciencia que, en estos autores se convierte en un dogmatismo positivista tan excluyente como el tan denostado integrismo católico. Este pretendido carácter científico del naturalismo fue defendido por Ernesto Bark, amigo y correligionario de López Bago y Sawa, a propósito de la narrativa de este último.

«Este carácter científico es esencial en la nueva escuela estética. Zola ha dicho terminantemente que sus novelas no son obras de fantasia escritas para deleitar, sino estudios sociológicos, reconstrucciones de la vida social, basados en documentos humanos.... ${ }^{23}$

Ernesto Bark se refiere al naturalismo como "literatura militante» y compara el estilo de Sawa con la oratoria guerrera de Napoleón I.

El espíritu militante, según López Bago, es el que le determina a combatir en El Cura el celibato eclesiástico «en lo que tiene de peligroso y bajo el punto de vista médico social» ${ }^{24}$. Con esta obra, como con La Prostituta, La Pálida y La Buscona, pretende su autor que sea «más agitado y vivo el movimiento de lucha entre la secta romántica y el proceder naturalista $»^{25}$. Para López Bago el naturalismo ha entrado en los ateneos antes de tiempo y no se encuentra cómodo aposentado en las poltronas académicas. El naturalismo debía recuperar el carácter revolucionario, "de barricada» y desembarazarse de los "cómodos sillones de terciopelo" y de las atildadas plumas que lo atenazaban:

«Para crecer tiene que luchar en las calles, ganar primero la opinión del pueblo, ser un héroe popular; su sitio no es la academia todavía.

SAWA, A.; Crimen legal, p. 267. Pp. 5-6.

BARK, E.: «El naturalismo español». (ierminal, 1, n." 19, 10 de septiembre de 1891 ,

Loplz Bago, E.: Apéndice a til cura. Novela médico-social, Madrid, Juan Muñoz y Compañia, s/a, p. 259

Ihidem, p. 262. 
Es algo mejor que esto. La barricada. Y a la barricada fue conmigo, $y$ en ella sigue hasta obtener el triunfos' ${ }^{26}$.

Nada más alejado de este tipo de literatura que la que López Bago denomina «novela bonita» y que estaría representada por obras como La Pródiga, El Escándalo, El Niño de la Bola, El doctor Faustino, López y su mujer... "iqué hermosos libros de boudoir! iqué ejemplares tan preciosos de la literatura para las damas! ¡Juan Valera proclamando en uno de sus estudios crticos las excelencias de la novela bonita! Frontaura escribiendo Las Tiendas dio la nota justa (...) ¡Las duquesas, las generalas, retratadas en miniatura sobre marfil! iya lo creo! ¡Renacimiento indudable! ${ }^{27}$. Estas producciones, de las que siempre se asegura que poseen un «estilo inigualable», no saben presentar personajes encarnados de humanidad sino "atildados figurines» Es «una literatura de frac inaguantable» ${ }^{28}$.

El escenario de este tipo de narraciones es casi siempre la región andaluza, y andaluces son igualmente los autores, los personajes y las situaciones. Se habla, en estas novelas, «de las batatas en dulce que hacen en Granada; de las yemas que hacen en Sevilla las monjas de San Leandro; yo no sé cuántas tacillas de almíbar toman los personajes durante su vida, y es incalculable el número de merengues que se come de una sentada la protagonista ${ }^{29}$.

Con todos estos ingredientes, el amor no resulta menos empalagoso y «la gratitud a las monjas confiteras hace que hombres y mujeres sean perfectamente católicos apostólicos romanos" ${ }^{30}$. La organización de todos estos materiales también obedece, según López Bago, a procedimientos no menos peregrinos, parecidos a esas "grandes invenciones que hacen fortuna en tiempos de feria: esos rompecabezas, encanto de los niños que tienen aptitud para las matemáticas, a juicio de los autores de sus días. La cuestión de los quince, El nudo gordiano, Las bolas chinas y otra porción de juguetes por el estilo. Es un enredijo de alambres y de hilos (los hilos de la trama), con lo cual, dejando la costura a un lado y dando paz a los frascos de tocador, pueden entretener las damas sus ratos de ocio: la novela bonita adquiere entre ellas otra cualidad, y pasa a ser lectura interesanten ${ }^{31}$.

Un requisito insoslayable en este tipo narrativo, que también fue un

Lopl /. Bago, E.: Apéndice a $E l$ Cura... pp. 262-26.3.

Ihidem, pp. 265-266.

Ihidem, p. 266.

Ibidem, p. 267.

Ibidem, p. 267.

Ibidem. p. 268. 
caballo de batalla para el naturalismo, lo constituye el tema de la moral. En la novela bonita la moralidad sigue las directrices de la ética romántica cuya receta, según López Bago, podría sintetizarse en los siguientes puntos: 1. La virtud queda siempre triunfante y el vicio muerto a sus pies; $2 .^{\circ}$ los buenos se casan al final, como sucede en el teatro.

La poca humanidad de que están dotados los personajes, sus comportamientos miméticos y automáticos imprimen a estas narraciones «una perfecta monotonía".

Todas estas artificiosidades deben ser rechazadas por los auténticos naturalistas. Por haber procedido de esta forma, han cosechado éxito las novelas de Pérez Galdós ${ }^{32}$. El traslado fiel de la naturaleza a la novela es lo que singulariza la escuela naturalista ${ }^{33}$. Ése es el proceder de Pérez Galdós y ése era el objetivo básico de la novelística de Zola. Este último autor es el auténtico paradigma, y el seguimiento de sus métodos no convierte a los discípulos en imitadores serviles o en sectarios sino en integradores de toda la heterogeneidad y diversidad que of rece la naturaleza:

«En qué imitamos a Zola? En una sola cosa, en la cual le imitan todos los seres humanos. En amar la naturaleza. En no proceder por segregaciones y exclusiones, apartando lo feo, desechándolo, sino cogiendo en el campo un gran manojo, en que vayan reunidas en maravilloso contraste las rosas y el jaramago, la adelfa y el tomillo, la dorada espiga y la amapola, todo junto, confundido y revuelto (...). Se nos acusa de ello como de un crimen. Se nos acusa de copiar la humanidad tal como es, y de que la lealtad de nuestra pluma consista en que no nos guste engañar a nadie» ${ }^{34}$.

$Y$ si tal procedimiento consiste en imitar a Zola, también lo imitaron los veristas italianos y autores portugueses como Eça de Queirós y del mismo modo se condujo Dickens en Inglaterra. Para corroborarlo, reproduce López Bago estas palabras del maestro francés: «Mostramos el mecanismo de lo útil y el de lo perjudicial; analizamos en él el determinismo de los fenómenos humanos y sociales, para que algún dia puedan dominarse y dirigirse estos fenómenos. En una palabra, trabajamos con todo el siglo actual en la gran obra, en la conquista de la materia, en el poder del hombre centuplicado» ${ }^{35}$.

Lóptz. Bacio, E.: Apéndice a El Cura..., p. 274.

"Ibidem, p. 288.

4 Ibidem, p. 288.

"I Ihidem, pp. 289-290. 
La pintura de la realidad lleva implícitos dos procesos previos: la observación y el experimento ${ }^{36}$. Sobre ellos vuelve López Bago en la introducción a su novela El separatista. Aquí expone los ideales del naturalismo que se concretarian en los siguientes puntos:

a) exposición desnuda de los acontecimientos,

b) observación y experimento aplicados con «inexorable indiferencia» ante los hechos que se relatan,

c) necesario auxilio de la ciencia para que la narración salga fortalecida,

d) mirada atenta puesta en la Naturaleza,

e) ausencia de deducciones y comentarios,

f) los personajes padecerán, gozarán y tendrán, en la novela naturalista, la misma vida que tienen en la realidad,

g) el novelista debe limitarse a copiarlos en «figura, pasiones, vicios, virtudes y lenguaje $)^{37}$, observando siempre, como norma, la fidelidad al referente,

h) la "expresión personal» debe ser la única originalidad que se permita el escritor,

i) hay que observar impersonalidad absoluta en la narración ${ }^{38}$,

j) la vitalidad ha de residir en la inteligencia y la fuerza en la verdad.

Este manifiesto está inspirado en las teorías de Zola, que López Bago reproduce en el apéndice a $L a$ Pálida $a^{39}$. Allí hace suyo el estudio crítico del naturalista francés acerca de Flaubert, donde se vuelve a insistir en los requisitos de la novela moderna:

LÓPEz Bago, E.: Apéndice a El Cura..., p. 289.

"López Bago, E.: El separatista, La Habana, Vda. de Pozo e hijo, 1895, «Al lector",

is Ibidem.

39 López Bago, E.: La Pálida, Madrid, Álvarez Hermanos, pp. 268-278. 
1. La narración debe ser una reproducción exacta de la realidad con ausencia de todo elemento ficticio.

2. $\quad$ La belleza de la novela ha de surgir de la plasmación de la verdad indiscutible del documento humano.

3. El autor debe desaparecer completamente detrás de la acción que cuenta $^{40}$.

Sobre las teorias de Zola vuelve en el apéndice de La Querida, aunque en este caso reproduce unos fragmentos del patriarca del Naturalismo sobre la poesía de Víctor Hugo, Lamartine, Gautier, Baudelaire, etc.

En el apéndice de La Buscona, como en el de La Pálida y en muchas otras obras, se refiere a los procesos que sufrieron sus escritos y a la actuación que tuvo contra él Raimundo Fernández Villaverde, gobernador de Madrid. Afirma con ironía que dicho político debía de ser un partidario ferviente del Romanticismo a juzgar por la saña que "contra mí despliega»". Ello le lleva a plantear una vez más el controvertido problema de la moralidad en el arte y de nuevo recurre a la autoridad del autor de Germinal: "Cuando un autor tiene talento, todo le está permitido - dice Zola-. Se lo permitimos a Rabelais en Francia, como se le permitió todo a Shakespeare en Inglaterra. Una página bien escrita tiene su moralidad propia, que está en su belleza, en la intensidad de su vida y de su tono» ${ }^{42}$. Añade López Bago que en España se les ha permitido todo a Cervantes, a Quevedo y a Tirso «y actualmente se permite todo al Sr. Valera, traductor de Dafnis y Cloe y también a Alarcón". Argumenta que sus obras no son inmorales y que otros libros como Doce cuentos en camisa, contados por una vengadora sí son pornográficos y sin embargo están autorizados ${ }^{43}$. Reproduce unas palabras de Zahonero, en las que, entre otras aseveraciones, se encuentran las siguientes: «Cumple aquí a las artes sujetarse severamente a la verdad, cumple al pintor que sirve a la anatomía y a la patología, no mentir un trazado, no engañar con un hermoso pero falso color (...). La razón se debe a la verdad y el sentimiento también. Al majestuoso desarrollo de una ciencia positiva debe responder el mudo respeto del artista" ${ }^{44}$. Finalmente López Bago dedica unas palabras a la estrechez económica en que vive el escritor en España y a las trabas que ate-

40 López Bago, E.: La Pálida, p. 281.

4 LOPEZ BAGo, E.: La Buscona. Novela médico-social, p. 244.

42 Ibidem, p. 245.

4. Ibidem, p. 256.

4 Ibidem, p. 272. 
nazan la libertad de expresión: «Ah, si los escritores españoles pudiéramos redactar nuestros libros en una quinta de recreo de nuestra propiedad, halagados por la fortuna y (lo que en Francia sucede) contando por segura la admiración de nuestros colegas, no luchando innecesariamente con estas tres cosas horribles, la envidia, la miseria y las trabas puestas a la libre emisión de ideas ${ }^{45}$.

No sienten estas trabas los cultivadores de «la novela bonita» como Pedro Antonio de Alarcón, al que López Bago pensaba replicar en el Apéndice a Carne importada por unas críticas vertidas por éste contra el autor de $L a$ Prostituta. La noticia de la muerte de Alarcón, que nuestro autor recibe en Buenos Aires, le obliga a retirar con pesar los originales y aprovecha entonces la ocasión para felicitar a Leopoldo Alas por Su único hijo. Esta obra es una «novela naturalista del género aquel que la crítica a lo Matoses y los gobernadores a lo Villaverde (no el torero) consideraba procesable ${ }^{46}$. López Bago se refiere a otras obras publicadas por estas mismas fechas como Pequeñeces del padre Luis Coloma o La espuma de Armando Palacios Valdés. Ninguna de ellas alcanza, para López Bago, la categoría de novela realista, naturalista o verista. No gozan del estatuto de la libertad, imprescindible en las novelas de este tipo ${ }^{47}$.

La novela Carne importada termina con una de las muchas sentencias naturalistas formuladas por López Bago: "Contar la verdad no es escribir cuentos divertidos $\|^{48}$. Este respeto a la verdad le lleva a utilizar en sus novelas palabras «no acostumbradas en letra de molde, desde los tiempos en que invadió nuestra hermosa literatura la falsa creencia de alarmarse en cuanto un autor imitaba en lo que sus fuerzas pudieran la franca manera de Cervantes, la de Quevedo y la de cuantos dieron a las letras castellanas su mayor brillo" ${ }^{49}$. Ilustra su afirmación con algunos términos empleados en su novela El separatista y de ello se justifica en su escrito "Naturalismos» inserto al final de esta novela. En la página 105 el viejo guerrillero don José Godínez prorrumpe con la exclamación «iCállate, carajo!». Este mismo vocablo aparece en Torquemada y San Pedro de Pérez Galdós, aunque mitigado, según López Bago por otras palabras de «igual número de silabas y consonantes con ella» como zancajo, pingajo, cuajo y renacuajo. A pesar del respeto que siente por el autor de Fortunata y Jacinta le parece este «miramiento" del escritor «trivial y propio de un naturalismo de camilla, de una naturalidad coja y derrengada" ${ }^{50}$.

4s López Bago, E.: La Buscona, 277.

${ }^{46}$ López BAgo, E.: Carne importada (Costumbres de Buenos Aires), Buenos Aires, Admón. Urbano Ribero, "La Maravilla Literaria», s/a, p. III.

4 Ibidem, p. IV.

4. Ibidem, p. 283.

4 LoPez BAGO, E.: «Naturalismos», en El separatista, pp. 293-294.

so Ibidem, p. 294. 
Frente a ese «naturalismo de camilla», el que defienden y practican López Bago y Sawa permite que los personajes se expresen libremente ${ }^{51}$ : «Entiendo que así debe ser y así proceder todo el que escribe letras para que se impriman, se publiquen y publicadas, pasen a ser dominio del comentario de las gentes. Entiendo que debemos preocuparnos de la retórica mucho menos que de la verdad $~^{52}$. De ahi el carácter de sátira del naturalismo, que a unos disgusta y a otros agrada ${ }^{53}$. López Bago concluye el artículo "Naturalismos" con unas palabras de Duranty en las que se vuelven a reiterar el concepto de reproducción exacta de la realidad, la defensa de la sencillez expresiva y la afirmación de que el Naturalismo lejos de ser una escuela literaria es una expresión franca y completa de las individualidades ${ }^{54}$.

El análisis de las novelas de López Bago constituye el mejor exponente de la postura teórica de Sawa sobre el Naturalismo. En ellas, según el autor de Iluminaciones en la sombra, quizá falte dibujo, pero sobra el color, "color temerariamente distribuido, hasta formar la más brillante mancha artística de nuestra moderna generación de noveladores»" ${ }^{53}$. Este color deslumbrante, este exceso de luz provoca en Sawa la misma impresión que los lienzos de la buena escuela veneciana. En el empleo de esta técnica le debe no poco López Bago a Daudet, "el gran colorista de Francia»".

Al comentar La Prostituta y La Pálida resalta Alejandro Sawa aquel principio naturalista, según el cual el autor debe ocultarse tras lo que narra para que sea la realidad la que dicte el discurso novelesco:

"La Prostituta y La Pálida son obras implacables, sin nervios y sin entrañas, inexorables, en que el autor se oculta por completo para que sea la realidad sola, pero la realidad más antipática, más odiosa, la realidad que mata al padre y deja a los hijos huérfanos, la realidad que parece cómplice de la infamia, quien hable en todas las páginas, y quien se agite, atormentadora, cobarde, en toda acción, en todo el argumento del libron" ${ }^{57}$.

La presentación de la «realidad más antipática» supone ya un proceso de selección, que invalida el principio de absoluta imparcialidad por parte

31 LOPEZ BAGo, E.: «Naturalismos», en El separatista, p. 284.

52 Ibidem, p. 285.

33 Jbidem, pp. 287-288.

s4 Ibidem, pp. 297-298.

"SAwA, A.: "Impresiones de un lector", en Apéndice a El Cura, de E. López Bago. p. 295.

36 Ibidem, pp. 303-304.

${ }^{97}$ Ibidem, p. 304. 
del autor, y el mismo Sawa reconoce que «esa sociedad que estudia López Bago en La Prostituta y en La Pálida es fea, esencialmente, monstruosa, y huele más a pus y a los desinfectantes de las salas clinicas que al aroma de los campos y al perfume indistinto de la verdadera naturaleza» ${ }^{58}$.

Sawa reconoce que entre los componentes de la realidad como «materia novelable» se encuentran los aspectos negativos: «El crimen es realidad, la navaja goteando sangre es realidad también, la madre que vende a su hija, el esposo que vende a su mujer....

Junto a estos elementos negativos, la realidad presenta otros aspectos de un signo marcadamente opuesto:

«Pero también es realidad la nube, las gasas de vapor que se metamorfosean en la atmósfera marcando sobre fondo azul dibujos fantásticos (...) la ilusión rosada o color de cielo meridional de los amantes de quince años; el amor, el vino bebido sin exceso, una buena comida y la apoteosis de la dicha humana; una mujer joven y espiritual que os diga a gritos después de las adorables confidencias al oído: "Yo te amo por esta noche y por siempre" $"{ }^{60}$.

La imparcialidad que debe guiar siempre al novelista obliga a no desdeñar estos otros componentes ya que «eso es también realidad y vale la pena de que sea descrita por todos los fotógrafos de la escuela naturalistan ${ }^{61}$.

El documento humano, que según Zola y otros autores, está en la base de la novela naturalista, es incorporado con ciertas matizaciones a la teoria de Sawa:

"iLe document humain!-El documento humano ¿es la mostruosidad? Entonces no hay ningún artista en la tierra, ningún amante de la belleza. Todos deben desertar de ella, matarse, suicidarse, antes que la terrible muerte los asesine a traición por la espalda $)^{62}$.

5R SAWA, A.: «Impresiones de un lector», en Apéndice a El Cura, p. 304.

s9 Ibidem, pp. 304-305.

Ibidem, pp. 305-306.

at Ibidem, p. 306.

${ }^{62}$ Ibidem, p. 306. 
El documento humano, insiste Sawa, no es lo feo, o no es sólo lo feo; es también lo bello, lo hermoso. Si el escritor naturalista se limitase únicamente a reflejar el lado negativo de la vida, estaría negando la esencia del fenómeno artístico. Lo feo, unas veces; lo bonito, otras; o una sabia combinación de ambos constituye la estética del documento humano: «Ese es el arte. Ni el color blanco, ni el color negro solo. El blanco y el negro combinados hasta la hermosura absoluta. Un claroscuro que no ha podido soñar Rembrandt» ${ }^{63}$.

Por esta razón valora más positivamente Sawa La Buscona de López Bago que La Prostituta y La Pálida. En la primera se ha alcanzado la síntesis propuesta y ha logrado su autor una solución admirable. Es verdad y belleza, vivante et moderne al mismo tiempo, como debe ser el arte a la altura del progreso al que ha llegado la Historia. Esta fórmula la ilustra Sawa mediante el diálogo artístico entre el eminente paisajista Jules Dupré y su primo Claretie, el cronista de Le Temps:

"N' oublie jamais - decía el pintor al novelista-que pour qu'une ouvre d'art soit bonne, il faut la traiter comme Dieu a traité a ses arbres: les racines dans la terre et la cime dans le ciel $\rangle^{\text {to }}$.

Alejandro Sawa irá acentuando progresivamente los aspectos idealistas e incluso desdeñará sus primeras obras escritas bajo la tónica naturalista en la década de los ochenta. En Iluminaciones en la sombra valora ya más la Leyenda que la Historia y asegura que «lo inventado es generalmente más bello que lo averiguado y que los personajes de Homero son más vivos «que la gran mayoría de nuestra generación ambiente»"

Aquí, sin embargo, nos interesan especialmente aquellas novelas, en las que se reflejan - como en las de López Bago - la exaltación de la ciencia experimental, la importancia concedida al medio y a las leyes genéticas, la crítica social, y otros principios del naturalismo radical a los que se ha hecho referencia más arriba. En Crimen legal, La mujer de todo el mundo, Noche, Declaración de un vencido, etc., de Alejandro Sawa y en La Prostituta, El Preso, El Cura, etc., de López Bago aparecen reflejados estos presupuestos teóricos. Se comprobará con algunos ejemplos.

${ }^{63}$ SAwA, A.: «Impresiones de un lector», en Apéndice a $E /$ Cura, pp. 306-307.

o4 Ibidem, p. 307.

6s SawA, A.: Iluminaciones en la sombra, ed. de Iris M. Zavala, Madrid. Alhambra, 1977, p. 167. 
El recurso a la ciencia experimental: Se manifiesta especialmente en la aceptación del criterio de autoridad de hombres de ciencia como Claudio Bernard y en el empleo frecuente de un léxico especializado de disciplinas experimentales como la medicina. Son constantes también las descripciones anatómicas y la presentación de funciones fisiológicas a veces con un detallismo innecesario.

Todas las novelas de Eduardo López Bago llevan como pórtico las siguientes palabras de Claudio Bernard, que constituyen una máxima positivista: «La moral moderna consiste en buscar las causas de los males sociales analizándolos y sometiéndolos al experimento».

La novela Crimen legal, de Alejandro Sawa, es considerada por López Bago, como exposición de un caso de medicina, un caso de distocia. En este libro se exalta la cirugía "ciencia exacta si las hay, tan exacta como la geometría cuando asegura que la distancia más próxima entre dos puntos es la recta que los une» ${ }^{66}$.

El léxico especializado de la medicina es frecuente en La Prostituta y en otras novelas de Eduardo López Bago ${ }^{67}$.

Esta continua apelación a la ciencia experimental no excluye las referencias a pensadores y filósofos de todas las épocas, ya sean orientales como Averroes, u occidentales como Descartes y Spinosa ${ }^{68}$.

La fuerza determinante del medio en la conducta de los personajes: Este factor, considerado por Hipólito Taine como uno de los elementos básicos que gobiernan la vida, ejerce una influencia decisiva en los personajes novelescos de Sawa y López Bago. Como ha explicado Mercedes Etreros ${ }^{69}$ el medio es el que hace sucumbir a Carlos en Declaración de un vencido de Sawa, a Estrella en La Pálida, a Miguel en La Buscona y a Juan Ruiz en El Preso, de López Bago. En esta última novela se afirma lo siguiente: «El contacto con los viles, envilece. El hombre cautivo retrocede del estado social y se aparta del derecho y de la vida fisiológica ${ }^{70}$.

El medio determina ya desde el nacimiento y la primera infancia la vida de los individuos. Así, la prostituta Noemí, amante de Ricardo en Crimen legal ha nacido y se ha criado en un burdel: "Yo creo que a mí me parió mi madre para ser honrada. Pero desgraciadamente mi madre no lo era; era una mujer de la vida, una mujer de cartilla, como se dice. Yo nací en una

\footnotetext{
* Sawa, A.: Crimen legal, Madrid, Juan Muñoz y Compañia, 1886, p. 64.

67 López BAgo, E.: La Prostituta. Novela médico-social, p. 23.

- Sawa, A.: Crimen legal, p. 65.

69 Etreros, M.: «El naturalismo español en la década de 1881-1891», op. cit., p. 116.

${ }^{70}$ Lopez Bago, E.: El Preso. Novela médico social, p. 123.
} 
casa como ésta, en una casa de mujeres malas...) A los tres años de edad, ya sabía yo de las cosas del oficio casi tanto como sé ahoran ${ }^{71}$.

La importancia de la herencia. Los naturalistas radicales, imbuidos por un ingenuo biologismo determinista, presentan unos personajes que no pueden sustraerse al influjo de las leyes genéticas. La herencia y el medio son las fuerzas que mueven y dirigen sus conductas. Así, en Crimen legal se escucha reiteradamente, como una verdadera obsesión, la frase maléfica: «El salto atrás». Juan recuerda siempre a aquel bisabuelo suyo, muerto en la horca por asesino y ladrón, cada vez que piensa en su hijo encanallado por la herencia ${ }^{72}$. En la primera parte de la novela Noche, Alejandro Sawa dedica varias páginas a referir los antecedentes familiares, con predominio de los biológicos, de don Francisco y de su esposa Dolores y más adelante se insiste: “ $\mathrm{OH}$, fatalidad, alma del mundo! ¡Determinismo, ley de la vida! ${ }^{73}$. Hay excepciones, como sucede con la prostituta Julia la gallega, de la que se dice en la novela Noche: «Era el suyo un caso de prostitución extraño. Un caso de prostitución más propio de la patología que de la fisiología. Sin antecedentes hereditarios que, a la fuerza, la obligaran a ser tan gran ramera...". Es el caso antítetico al expuesto más arriba de Noemí, nacida y criada por su madre en el burdel.

Las fuerzas de la herencia y del medio no se contrarrestan sino que se incrementan mutuamente como sucede en Noche de Alejandro Sawa:

«Era, pues, don Francisco, una antinomia completa. Naturaleza de bruto y de curial al mismo tiempo, y según las ocasiones. Estas son las circunstancias que en antropogenia se llaman de herencia. Las de adaptación fueron peores.... ${ }^{74}$

Anticlericalismo radical: Es un componente básico de la novela naturalista de Sawa y López Bago. En este último el anticlericalismo aparece una veces sugerido y otras de forma más explícita, como en El Cura, donde se ataca el celibato, con un propósito semejante al que inspiraba a Zola en

1 SAwA, A.: Crimen legal, pp. 126-127.

72 Ibidem, p. 193.

13. Sawa, A.: Noche, Madrid, Biblioteca del Renacimiento Literario, 1888, p. 194.

74 Ibidem, p. 13. 
La Faute de l'abbé Mouret, aunque, según López Bago, «el maestro no desplegó en esta obra toda la fuerza que caracteriza sus ataques... $)^{75}$.

Sawa también incluye en sus novelas furibundos ataques contra el clero. En La mujer de todo el mundo la condesa de Zarzal seduce a don Felipe para conseguir sus propósitos. El tal don Felipe «pertenecía a ese género especial de curas híbridos que no ha previsto ninguna legislación canónica»" ${ }^{76}$; para él la vida "no era en realidad sino un festín permanente»"

El componente anticlerical es esencial en la novela Crimen legal, en la que se hace responsable a la institución eclesiástica de los males que sufren los protagonistas.

En Noche se asiste a la brutal violación de Lola por parte del cura don Gregorio, cuyo confesionario se había convertido en una cátedra de libertinaje: "No respetaba nada la voracidad satiríaca del confesor".

En algunas de estas novelas se utiliza la Biblia como un instrumento de seducción:

«La Biblia, el libro de Dios fue el galeoto. Uniéronse sus labios en ósculo infinito, y alli, a presencia de aquella hermosa naturaleza que recorría el tren sin detenerse un solo punto, quedó realizado el santo misterio de la generación de los seres» ${ }^{78}$.

López Bago reprueba a Sawa, que Ricardo, el protagonista de Crimen legal, recurra a la lectura del Cantar de los cantares para vencer la resistencia de Rafaela ${ }^{79}$, pero el mismo artificio y con idéntico propósito emplea el propio López Bago en su novela $E l$ Cura ${ }^{80}$.

La intención anticlerical de Criadero de curas, de Alejandro Sawa, va dirigida fundamentalmente contra los internados religiosos, iniciando un camino por el que más tarde transitaria $A . M$. D. G. de Pérez de Ayala. Sawa no desaprovecha la ocasión para atacar el dogmatismo, la intolerancia y el oscurantismo. El capítulo II, en el que se produce el ingreso de Manolito en el seminario, se titula significativamente "Ingreso en la sombra»". Si el anticlericalismo es una constante de su novelística, en esta obra alcanza la

"s López Bago, E.: El Cura, p. 261.

7 SAwA, A.: La mujer de todo el mundo, ed. citada, p. 33.

$"$ Ibidem, p. 34.

78 Sawa, A.: Crimen legal, p. 42.

"López BAGO, E.: Apéndice a Crimen legal, p. 272.

LOPEZ BaGo, E.: El Cura, p. 255.

s) Sawa, A.: Criadero de curas, Madrid, El Motín, Imprenta Popular, 1888. 
categoría de protagonista. Cuando los curas se reúnen para decidir la postura que deben adoptar ante la fuga de Manolito, Sawa los compara con «un pelotón de inquisidores» ${ }^{82}$.

Allén Phillips sugiere que «Banderín de enganche» ${ }^{83}$ podría ser un texto rehecho de la novela Criadero de curas, cuya narración, según confiesa el crítico citado, no ha llegado a conocer ${ }^{84}$. Esta tesis no resulta inverosímil ya que en otras ocasiones Sawa aprovechó y reutilizó sus textos; sin embargo, en este caso las obras tienen poco en común, si se excluye el ingreso de ambos protagonistas en el seminario a la muerte de sus padres. Las dos narraciones siguen luego un desarrollo diferente.

La crítica social. En el credo naturalista de López Bago ocupa este componente un lugar importante, y en sus novelas, como en las de Sawa, tiene reservado un papel destacado. Todas las narraciones del primero llevan el subtítulo de «novela médico social» y tres de las de Sawa (Noche, Declaración de un vencido y Criadero de curas) son denominadas por su autor «novelas sociales».

Alejandro Sawa, en la dedicatoria de La mujer de todo el mundo a su hermano Enrique, califica su libro como un caso de patologia social y en la «Nota al lector", inserta en Declaración de un vencido, afirma que su protagonista fue víctima injusta de la sociedad y sostiene que las páginas de la novela "pueden servir de pieza de acusación el día, que yo creo próximo, en que se entable un proceso formal contra la sociedad contemporánea». En Noche se insiste en lo mismo.

En Luces de bohemia de Valle Inclán se alude ya el carácter social de la narrativa de Sawa, y Zamora Vicente ${ }^{85}$ y Allen Phillips ${ }^{86}$ han vuelto sobre ello.

El propósito que anima las narraciones del naturalismo radical consiste en trascender la idea de mero pasatiempo para convertirse en el estudio serio y detallado de algún problema social. Se tiende, pues, a la presentación de casos y en este sentido se trata de verdaderos documentos humanos. Lo mismo que Zola, entienden la novela como corolario de la sociología.

Erotismo. El componente erótico es llevado en las novelas de Sawa y

82 SAwA, A.: Criadero de curas, p. 64

${ }^{83}$ SAwA, A.: "Banderín de enganche», en la revista Don Quijote, II, n. 30,27 de julio de 1894, p. 1 .

${ }^{84}$ Phillips, A.: Alejandro Sawa..., op. cit., p. 227.

ss ZAMORA VICENTE, A.: Edición de Luces de bohemia de Valle Inclán, Madrid, EspasaCalpe, 1973.

${ }_{86}$ PHILlips, A.: op. cit., p. 162. 
López Bago hasta extremos desacostumbrados. En esta misma línea, aunque con tonos más suaves, se orientaría más tarde la narrativa de Felipe Trigo, Eduardo Zamacois y otros autores.

Los personajes femeninos de López Bago llegan a tal degeneración en el aspecto sexual que son presentados frecuentemente saliendo de un prostíbulo para entrar en otro, o abandonando ese prostíbulo para vivir amancebados con un noble. Los masculinos son víctimas de la lascivia que con frecuencia les lleva a contraer las más terribles enfermedades, como le sucede al marqués de Villaperdida, propietario del lupanar donde se desarrolla la acción de $L a$ Prostituta. El dinero que el marqués conseguía con este negocio y con el de. otras treinta y nueve casas más era enviado al Papa en penitencia por haber matado a su mujer al contagiarle una enfermedad venérea. Y si este personaje nos resulta poco verosimil, López Bago asegura, en el apéndice titulado "La novela moderna según Zola», que responde a un tipo nuevo "real y muy corriente en esta tierra española» ${ }^{87}$.

En El Cura, las mujeres bíblicas como Eva, Sara, Rebeca, Dalila e historias como las de Amnón y Thamar avivan la sexualidad del sacerdote Román, y más tarde, animado por el cura vecino, Don Fermín y su supuesta sobrina Anita, consumará el incesto con su hermana Gracia.

Agustina, la protagonista de Carne importada es víctima de la trata de blancas, «negocio redondo, y realizado en todas sus partes de una manera magistral ${ }^{88}$. La prostitución en Buenos Aires, según López Bago, está sujeta a reglamentos y alcanza refinamientos extremos. Como en otras ocasiones, el autor asegura que todo lo expuesto es «de completa certeza y copia fiel de la realidad ${ }^{89}$.

Y si El confesionario de López Bago llevaría el subtítulo de "satiriasis», el erotismo de las novelas de Alejandro Sawa llegan, según Allen Phillips, «a los extremos de la más desenfrenada satiariasis»" ${ }^{90}$. En Crimen legal, la sexualidad alcanza extremos de locura en la casa que Ricardo «ha puesto» a la prostituta Noemi ${ }^{91}$.

La depravación sexual es responsable en Noche de la bestial violación de Lola por su confesor, el lascivo y bruto sacerdote Don Gregorio.

Situaciones parecidas se repiten en otras novelas como La mujer de todo el mundo. Y aunque se trata de escenas «que la novela si ha de ser honrada no podrá describir nunca» ${ }^{92}$, Sawa no ahorra ningún lujo de detalles en su presentación.

\footnotetext{
87 Lopez Bago, E.: La Prostituta, pp. 199-200.

" López BAGo, E.: Carne importada. Novela médico-social, p. 157.

89 Ibidem, pp. 157-158.

9 PHIlliPS, A.: op. cit., p. 171.

91 Sawa, A.: Crimen legal, p. 162.

92 SawA, A.: La mujer de todo el mundo, p. 82.
} 
Pesimismo extremado: El tono pesimista no es una característica del naturalismo según Leopoldo Alas. De distinta forma opinan Pardo Bazán, González Serrano y el propio Zola, para los cuales no es que todas las narraciones naturalistas desprendan pesimismo, sino que, como explica Zola, si «la honradez humana no existe en mayor cantidad que la salud perfecta" y "en todos nosotros hay un fondo de animal humano, al igual que hay un fondo de enfermedad $~^{93}$, resulta inevitable presentar los aspectos negativos de la vida. Sin embargo, en Sawa y López Bago, el pesimismo, como otros muchos aspectos, reviste unos caracteres exagerados. Más arriba se han reproducido unas palabras de López Bago, según las cuales para él y para Sawa, la definición que mejor conviene a la sociedad es la de «canalla». El pesimismo es un ingrediente de las novelas de Sawa, cuyos títulos ya delatan el tono de la narración: Noche, Crimen legal, Declaración de un vencido... En esta última exclama Carlos, el protagonista: «Era necesario sucumbir. Ni la embriaguez me daba el consuelo que pedía ${ }^{94}$. Y al final se despide de Carmen y de la vida, convencido de que «no hay otro canalla latente que la sociedad ${ }^{95}$. El pesimismo de estos autores se pone también de manifiesto en lo gris, sombrio y triste de muchas descripciones.

Tendencia al feísmo: La presencia de lo desagradable se manifiesta incluso por la tendencia a sustituir en algunos casos lo fisiológico por una puesta de relieve de los componentes más repugnantes del ser humano, como ya observó Mercedes Etreros ${ }^{96}$. Algunas de estas caracterizaciones grotescas hacen pensar en los modos expresivos perfeccionados más tarde por Valle Inclán en sus esperpentos y por algunos cultivadores del tremendismo.

El proceso de degradación que en las novelas de Sawa y López Bago, sufren algunos personajes que les lleva a la animalización y a la cosificación, como sucede con el amante desdeñado en La mujer de todo el mundo: «... aquel infortunado que había sido un hombre, convertido ahora en harapo, en desperdicio, en detritus, por el amor, esa cosa magnífica como dicen los poetas ${ }^{\text {p7 }}$.

Esta orientación descriptiva se encuentra igualmente en la presentación de ciertos elementos de la naturaleza y en la elección de determinados objetos con connotaciones negativas. Así, La sima de Igúzquiza, de Sawa, co-

${ }^{93}$ ZoLA, E.: El naturalismo, selección, introducción y notas de Laureano Bonet, Barcelona, Península, 1972, p. 123.

94 Sawa, A.: Declaración de un vencido, Madrid, Administración de la Academia, 1887, p. 225.

95 Ibidem, p. 238.

\% Etreros, M.: op. cit., p. 118.

97 SawA, A.: La mujer de todo el mundo, p. 178. 
mienza con esta descripción: «Era el anochecer; el anochecer de un día lluvioso, gris, sin horizontes. Se había echado encima la hora del crepúsculo, casi por sorpresa y los manojos de sombra de la noche hacían su irrupción» ${ }^{98}$. Y un poco más adelante: «El farol rojo que anunciaba al caminante la venta del Palomero parecía en aquellos lugares desolados un ojo sangriento, inmóvil de terror (...). Dentro de la venta, la tristeza era también infinita, medio alumbrada la sala del consumo por un farolillo de luz agonizante que, más bien que destruir, aumentaba la intensidad de las tinieblas) ${ }^{99}$.

En contraste con la anterior, se encuentran descripciones de una naturaleza lírica e idealizada y la mujer asume rasgos embellecedores. En Sawa, la mujer es presentada con la técnica parnasiana de las trasposiciones artísticas, procedimiento de época, quizá aprendido de Gautier, como observa Phillips ${ }^{100}$. Así, en La mujer de todo el mundo, la desposada tiene «la frente pulida, mimosamente pulida, baja y estrecha y con esas entonaciones suavisimas de color pálido que se admiran en el marfil antiguo; semejante por su forma a la de las Venus griegas... los ojos negros y sombrios, árabes por la expresión voluptuosa de la mirada y la magnífica dilatación de los párpados... ${ }^{101}$.

Sorprenden en algunos casos la similitud entre las descripciones de estos autores, como sucede con la imagen de Cristo en la cruz, que aparece en El Cura de López Bago ${ }^{102}$ y en La mujer de todo el mundo de Sawa ${ }^{103}$. Bastante semejanza ofrecen igualmente ciertos rasgos formales, cuyo análisis prolongaría en exceso este trabajo.

Los aspectos señalados ponen de manifiesto que tanto Sawa como López Bago llevan a sus últimas consecuencias las teorías de Zola, aunque como es obvio y como ya apuntó Clarín ${ }^{104}$, la culpa de sus excesos no la tiene Zola. La tiene una visión sesgada de la vida y de la literatura, una visión tan fanática según Ivan Lissorgues ${ }^{105}$, como la del integrismo católico que ellos atacan. Sin embargo, no podemos trazar una imagen completa de la estética naturalista si no integramos en su estudio la teoría y la obra de estos representantes de su vertiente radical.

98 SAwA, A.: La sima de Igúzquiza, Madrid, El Motín, 1888, p. 13.

99 Ibidem, pp. 15-16.

100 Phillips, A.: op. cit., p. 173.

101 Sawa, A.: La mujer de todo el mundo, p. 44.

102 López Bago, E.: El Cura, p. 21.

103. SAwA, A.: La mujer de todo el mundo, p. 49.

104 ALAS, L: "A muchos y a ninguno», en Mezclilla, pp. 176-186.

is Lissorgues, I.: "El 'naturalismo radical": Eduardo López Bago (y Alejandro Sawa)», en Yván Lissorgues (Ed.) Realismo y naturalismo en España en la segunda mitad del siglo XIX, Toulouse-Barcelona, Université de Toulouse -le Mirail- Editorial Anthropos, 1988, p. 250. 